\title{
AS MARCAS DO HUMANO: PISTAS PARA O CONHECIMENTO DA NOSSA IDENTIDADE PESSOAL*
}

Angel Pino ${ }^{1}$

\begin{abstract}
RESUMO: Neste artigo, o Professor Angel Pino problematizou o paradoxo da natureza humana do homem, ao analisar como os sentidos do adjetivo humano podem qualificar tal natureza. Ao indagar sobre como o ser biológico se transforma em ser humano pela ação da cultura que ele próprio produz, o autor buscou expandir e adensar os argumentos na perspectiva do materialismo histórico e dialético e discutir as implicaçóes das teses vigotskianas sobre a emergência histórica e cultural das funçôes psicológicas especificamente humanas, da dimensão simbólica, da consciência. Ao admitir a contradição inerente às relaçóes naturezacultura e comentar sobre as possibilidades atuais da biotecnologia na ciência contemporânea, Pino elaborou conceitualmente sobre a atividade criadora do homem, procurando explicitar como as marcas do humano, marcas da história e da cultura, se inscrevem e se tornam constitutivas do funcionamento orgânico na espécie Homo. Apontando para a complexidade da condiçáo humana, o autor ainda teceu consideraçóes sobre as implicaçóes éticas dessa condição.
\end{abstract}

Palavras-chave: Relações natureza-cultura. Condição humana. Perspectiva histórico-cultural.

THE MARKS OF HUMAN: CLUES TO LEARNING OUR PERSONAL IDENTITY

ABSTRACT: In this article, Professor Angel Pino brought the paradox of human nature of man to the fore, analyzing how the meanings of the adjective human can qualify this nature. Inquiring about how biological beings become human beings by the action of the very culture they produce, the author attempted to expand and deepen arguments from the perspective of historical and dialectical materialism, while discussing the implications of the Vigotskian theses on the historical and cultural emergence of specifically human psychological functions in the symbolic dimension of consciousness. Assuming the inherent contradiction in nature-culture relations and commenting on the current possibilities of biotechnology in contemporary science, Professor Pino elaborated concepts on the creative activity of man, seeking to explain how specifically human marks, marks of history and culture become

\footnotetext{
*Trabalho inicialmente apresentado no XII Encontro de Didática e Prática de Ensino, (ENDIPE), Curitiba, 2004.

${ }^{1}$ Universidade Estadual de Campinas, Faculdade de Educação (in memoriam - 1933-2013). DOI: 10.1590/ES0101-73302018191029
} 
inscribed in and constitute the organic functioning of the Homo specie. By pointing the complexity of the human condition, the author also makes remarks about its ethical implications.

Keywords: Relations nature-culture. Human condition. Historical cultural perspective.

\section{LES MARQUES DE L'HUMAIN: DES INDICES POUR CONNAÎTRE NOTRE IDENTITÉ PERSONNELLE}

RESUMÉ: Dans cet article, le professeur Angel Pino problematise le paradoxe de la nature humaine de l'homme, en analysant comment les sens de l'adjectif humain peuvent qualifier une telle nature. En s'interrogeant sur la façon dont l'être biologique devient un être humain par l'action de la culture qu'il lui-même produit, l'auteur a essayer d' élargir et approfondir les arguments du point de vue du matérialisme historique et dialectique, et discute aussi des implications des thèses de vigotskiennes sur l'émergence historique et culturel des fonctions psychologiques spécifiquement humaines, de la dimension symbolique, de la conscience. En admettant la contradiction inhérente à la relation nature-culture et en faisant des commentaires sur les possibilités actuelles de la biotechnologie dans la science contemporaine, Prof. Pino a conceptuelment élaboré sur l'activité créatrice de l'homme, en essayant d'expliquer comment les marques humaines, les marques de l'histoire et de la culture, font partie et devient constitutives du fonctionnement organique dans l'espèce Homo. Soulignant la complexité de la condition humaine, l'auteur a encore fait des considérations sur les implications éthiques de cette condition.

Mots-clés: Relations nature-culture. Condition humaine. Perspective historique-culturelle.

\section{Palavras iniciais}

"As marcas do humano", título deste trabalho, é uma espécie de logotipo das questóes que, nos últimos anos, vêm sendo meu objeto de investigação, provocado pelas instigantes teses de $V_{y g o t s k y}{ }^{1}$ a respeito da natureza humana, particularmente duas delas, cujo interesse teórico transborda o campo da psicologia em que foram inicialmente pensadas e cujas implicaçóes ecoam no debate contemporâneo sobre a condição humana. A primeira tese é a que sustenta que as funçóes psicológicas que definem a especificidade humana do homem são de natureza cultural. Lembrando que, para Vygotsky (1997, p. 106), "cultura é o produto, ao mesmo tempo, da vida social e da atividade social do homem" ${ }^{2}$, o que, no contexto da matriz teórica que inspira seus trabalhos, equivale a dizer que é o conjunto das 
produçôes dos homens. A segunda tese, decorrente dessa, é a que sustenta que essas funçóes são de origem social (VYGOTSKY, 1997, p. 106) ${ }^{3}$, ou seja, que se constituem em cada indivíduo como resultado da sua inserçáo no meio humano ou, em outros termos, nas condiçóes de existência, sociais e culturais, criadas pelo próprio homem.

A versão final dessas duas teses é a resposta que Vygotsky dá à pergunta que ele mesmo se coloca $O$ que é o homem?: para nós, diz ele, é o conjunto de relaçôes

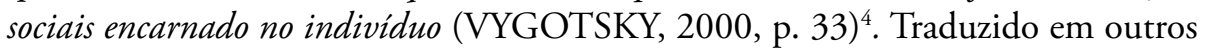
termos, isso quer dizer que o humano do homem é obra do próprio homem. Descartam-se assim todas as concepçóes de homem que oscilam entre as que o reduzem a uma mera materialidade biológica, mesmo mais complexa do que as outras, e as que fazem dele um ser transcendental — de origem sobrenatural ou metafísica - suportado por uma materialidade biológica.

O instigante das teses de Vygotsky são as consequências, teóricas e práticas, que decorrem delas, as quais têm muito a ver com o sentido do que se convencionou chamar natureza humana, uma expressão em que o bumano qualifica a natureza. Destaco apenas duas consequências:

- $\quad$ se as funçóes especificamente humanas não são obra da natureza, mas da cultura, e se a cultura é obra do homem, conclui-se que o que há de humano no homem é obra dele, com todas as implicações que isso tem para uma concepção do humano;

- mas se as funções especificamente humanas são obra do homem e este é um ser da natureza, como explicar que o humano não seja obra da natureza? Estamos, certamente, diante de um paradoxo, razão principal das dificuldades de entender o que é o bumano.

Creio que a mais importante tentativa de solução desse paradoxo coube a Marx (1977, p. 136), com a sua teoria do trabalho social esse ato que se passa entre o homem e a natureza exterior pelo qual, agindo sobre a natureza exterior e modificando-a, o homem modifica sua própria natureza. Ou seja, a ação do homem póe frente a frente a natureza e uma parte dela, provocando transformaçóes nela que não são obra dela. $\mathrm{O}$ paradoxo revela, portanto, uma contradição que escapa à lógica identitária, como diria Castoriadis (1975), pois, por princípio, nada do contido no todo, no caso a natureza humana, pode agregar a esse todo algo que não seja obra dele.

Uma explicação que, se não dissolve a contradição, a resolve dialeticamente, é que esse ser da natureza, ao desgarrar-se da família dos primatas e seguir uma via evolutiva própria, tornou-se capaz de fazer dos meios naturais que possibilitavam sua ação meios simbólicos que lhe permitiram conferir à ação e aos 
seus produtos uma forma nova de ser: a forma simbólica. Foi um grande mérito de Vygotsky pôr em evidência a analogia existente entre a invenção e o uso de meios materiais de ação - como já ocorre em escala limitada no mundo animal - e a invenção e o uso de meios simbólicos - particularidade exclusiva de Homo - retomando as ideias de mediação e de dialética de Hegel na perspectiva materialista de Marx e Engels.

É deste paradoxo e das tentativas de explicação na perspectiva do materialismo histórico e dialético que este texto trata. Como pode inferir-se já do próprio título, o objeto em discussão não é propriamente o homem, subjetividade concreta, mas o bumano definidor da sua natureza. O sentido em que é tomado o termo humano aproxima-se em parte daquele que parece ter em Nietzsche quando fala de "humano, demasiado humano", utilizando-se dessa ideia como ponta de lança para fustigar com os seus aforismos o que de "não humano" ele vê no homem europeu, com suas tradiçóes, costumes e práticas civis e religiosas. Há, porém, uma diferença: o que parece que para ele é "não humano", aqui faz parte também do humano, cujos limites metafóricos são representados pelas figuras do anjo e do demônio, estes sim situados fora do campo do humano, em que os contrários se excluem e a liberdade não opera.

Humano, demasiado humano - nos diz Nietzsche em Ecce homo, livro publicado dez anos depois daquele - é o monumento de uma crise. Ele se proclama um livro para espíritos livres: cada frase ali expressa uma quase vitória — com ele me libertei do que não pertencia à minha natureza. "[...] Em nenhum outro sentido a expressão "espírito livre" quer ser entendida: um espírito tornado livre, que de si mesmo de novo tomou posse" (NIETZSCHE, 1995, p. 65).

\section{A questão do humano}

O termo humano evoca uma temática que, desde a Renascença, reaparece com frequência no pensamento ocidental e que nos tempos atuais retorna com força maior na forma de alertas, lançados por diversos cientistas, do perigo, caso o avanço da biotecnologia escape ao controle dos homens, de uma "explosão do humano", não necessariamente pela extinção da espécie humana por acidentes nucleares ou catástrofes naturais em grande escala - o que não está totalmente excluído - , mas pela possibilidade real de ocorrerem nela profundas transmutações biogenéticas produzidas por manipulaçôes genéticas e implantes biônicos microscópicos. A expressão mais radical desses alertas talvez seja a obra do astrônomo britânico Rees (2003), a qual, em pouco mais de duzentas páginas, tenta mostrar não só a persistência da ameaça nuclear e do recurso às armas químicas, como, sobretudo, as consequências dos avanços inevitáveis no campo da biotecnologia e da nanotecnologia, tornando realidade o que, ainda há algumas décadas, parecia pura ficção: a criação e o implante de autômatos microscópicos no organismo humano, 
assumindo o controle das funções específicas do homem. O resultado previsível disso é a possibilidade de "transmutação da espécie", inaugurando o que está se convencionando chamar de "nova era evolutiva pós-humana". Nessa mesma linha de raciocínio, situa-se o artigo de Kurzweil (2003), em que ele apresenta o que poderá ser uma nova versão do "ser humano", na qual componentes biônicos microscópicos substituiriam grande parte das estruturas biológicas, sendo capazes, por sua vez, de trocar órgáos vitais e de assumir de forma autônoma funçóes fisiológicas e neurológicas. Essa eventualidade leva outros autores a se questionarem a respeito dos conceitos de liberdade e de dignidade humanas.

A questão de fundo nesses e em outros trabalhos sobre o mesmo tema ${ }^{5}$ é a da natureza humana, a qual sintetiza as diferentes concepçóes que circulam nos meios científicos e filosóficos a respeito da relação "homem ó natureza". Em última análise, o que está em jogo é a própria concepção do que é o humano.

O sentido que esse termo tem neste trabalho afasta-se, igualmente, tanto daquele que the confere os discursos caracterizados pela exaltação do humano como expressão de uma visão transcendental do homem, qualquer que seja a razão invocada (religiosa, metafísica ou simplesmente romântica) — quanto daquele que lhe é dado em discursos caracterizados pela negação niilista ou cética do significado do bumano como atributo do homem, em razão, sobretudo, dos inúmeros aspectos sombrios de sua história e das múltiplas formas destrutivas e predatórias que marcam muitas das suas relaçóes com seus semelhantes e com a natureza.

Os contornos semânticos do termo humano na perspectiva deste trabalho são bem precisos, nada tendo a ver com os velhos humanismos. Em síntese, ele designa esse ponto indescritível na relação homem ó natureza em que ocorre a emergência da consciência. Vale relembrar que as teses de Vygotsky que inspiram essas reflexôes situam-se no contexto do materialismo histórico e dialético, na linha de Marx e Engels, em que a emergência da consciência é um fenômeno historicamente situado e ligado à atividade criadora do homem. A consciência, entendida não como uma entidade, mas como uma função semiótica - Bakhtin a identifica com o signo — , surge no distanciamento do homem da natureza da qual faz parte, mas sem abandonar sua condição natural, o que lhe permite fazer dela o objeto da sua ação técnica e simbólica. Isso quer dizer que a consciência emerge no agir humano, sendo ao mesmo tempo causa e efeito desse agir. Ora, o próprio da atividade humana é que ela é simbólica além de técnica, produzindo um efeito de simbolizaçấo em tudo que ela opera. Ora, é inerente do simbólico transformar as coisas sem subtrair-lhes sua natureza. Isso implica várias coisas:

- nem a natureza e nem o homem perdem sua condiçáo natural ao adquirirem formas simbólicas de existência;

- $\quad$ essas formas novas têm significação para ele, homem, não para ela, natureza; 
- $\quad$ se no plano natural o homem é obra da natureza, no plano simbólico a natureza é obra do homem.

Isso conduz a conceber a relação homem ó natureza de uma forma dialética capaz de projetar nova luz ao debate do humano, pois se o homem não perde sua condição de natureza ao tornar-se humano, é possível pensar que nele a natureza se transforma a si mesma. Em outras palavras, isso quer dizer que no homem - essa infinitamente pequena partícula da matéria viva que compóe a infinitamente pequena parte da matéria inorgânica que constitui a imensidão do universo - a natureza adquire consciência de si mesma, atingindo o patamar de evolução mais alto que se conhece até agora.

Pensando em termos de uma possível "era evolutiva pós-humana", como anunciam os profetas da ciência contemporânea, poder-se-ia pensar que essa nova era tanto poderia significar a extinção da "luz da consciência" na natureza no caso de uma extinção catastrófica da espécie humana — quanto a emergência de formas novas de consciência — no caso de transmutaçóes biogenéticas produzidas pelo próprio homem. É nessa relação dialética homem ó natureza, na qual se inscreve a associação natureza ó cultura, que se situa o lugar do debate que o termo humano levanta neste trabalho. Não é difícil perceber que em uma perspectiva como esta não há lugar nem para exaltaçóes românticas do "humano" nem para niilismos e ceticismos negadores do lugar do homem na natureza como consciência dela.

\section{A questão das marcas}

A temática das marcas surge quando, na discussão das teses de Vygotsky (1997, p. 106) sobre a natureza e a origem das funçóes especificamente humanas cuja emergência ocorre em dois planos $^{6}$, o social e o pessoal, e em dois tempos, um antes e um depois — interrogamo-nos não só a respeito da maneira como um ser biológico transforma-se em um ser humano sob a ação da cultura e permanecendo biológico, mas também e, sobretudo, a respeito das consequências dessa transformação. Em outras palavras, nos questionamos a respeito da maneira como ocorre o encontro das funçôes biológicas e das funçóes culturais - aquelas formando o rio da vida construído pela natureza, estas formando o rio do simbólico, inventado pelo homem. Um acontecimento cuja metáfora mais bela é a do "encontro das águas" como no caso do Tocantins e do Solimóes. Se a metáfora não nos traísse por ocultar por trás da diferença de cursos e colorações a mesma identidade da água, poderíamos dizer que os rios da vida e do simbólico mesclam-se para dar origem a um novo rio que, sem perder suas características da vida, torna-se uma forma diferente de vida. A vida e o simbólico fundem-se, sem confundir-se, para constituir a vida humana. 
No desenvolvimento da criança estão representados (não repetidos) dois tipos de desenvolvimento mental que encontramos de maneira separada na filogênese: o desenvolvimento do comportamento biológico e histórico, ou natural e cultural. Ambos os processos encontram na ontogênese seus análogos (não paralelos). Este é o fato básico e central [...] ( $\mathrm{Na}$ criança normal) ambos planos de desenvolvimento - o natural e o cultural coincidem e se fundem. Ambas as ordens de mudanças se interpenetram e formam essencialmente uma ordem única de formação social-biológica da personalidade da criança (VYGOTSKY, 1997, p. 19-20).

A questão que se desprende disso, e que não foi claramente explicitada por Vygotsky (1997), é que a natureza biológica que cada um herda dos seus genitores já leva as marcas da cultura, pois é natureza transformada ao longo da história filogenética da espécie. Marcas necessárias para que o processo de constituição cultural de cada novo indivíduo da espécie, cujo começo verificável se situa após o nascimento, possa acontecer. Do contrário, nem o processo biológico ultrapassaria os limites impostos pela natureza, nem o cultural poderia entrar em operação por falta de adequação da natureza. Para que as funções culturais possam entrar em operação é necessário que encontrem o suporte bioneurológico necessário. Algo semelhante deve ocorrer com as funçóes biológicas: para que elas possam adaptar-se ao funcionamento cultural imposto pelo meio humano devem dispor de alguns dispositivos biogenéticos que permitam essa adaptação. A presença prévia dessa espécie de "configuração" cultural do organismo no início do desenvolvimento da criança constitui um postulado lógico: é condição para que ele possa funcionar quando exposto ao impacto da cultura e esta possa encontrar as condiçóes de operar.

Mas que marcas são essas que possam nos permitir identificar a presença do humano em organismos cujo modo de funcionar é ainda visivelmente biológico, como ocorre com a criança nos primeiros momentos (horas, dias, semanas, meses de vida extrauterina? Como pretender identificar marcas do bumano quando o que observamos é um modo natural de funcionar? Depois de ocorrer o "encontro das águas", como distinguir as que são de um ou de outro rio se elas são inseparáveis? Sabemos, porém, que as águas diferentes estão lá. Da mesma forma, uma vez que os dois cursos de evolução se encontram e se fundem na história do ser humano, é difícil separar o que é obra da natureza e o que é obra da cultura. Sabemos, porém, que se não podemos separar mais os dois fluxos evolutivos, conhecemos os limites de cada um separadamente: ao que a natureza conduziu os outros primatas e ao que a cultura conduziu a natureza no caso de um deles: o homo sapiens. Poderíamos pensar que o problema da relação natureza ó cultura estaria resolvido, não soubéssemos que o homem é, ao mesmo tempo, origem e resultado do seu encontro da natureza e da cultura que ele mesmo operou. Assim, voltamos ao mesmo ponto de partida. 
Falar em marcas do humano é discorrer sobre aquilo que testemunha a ação desse ser que representa o pico de evolução da natureza, pico que talvez possa ser suplantado. É falar do que significa para ele ter possibilitado a emergência da consciência e, com ela, das múltiplas opçóes que se abriram para ele de pensar e de agir com suas consequências imprevisíveis, pois não faz sentido nenhum fazer do humano o registro unicamente das açóes que atendem aos padróes do "homem bom", definidos por uma dada sociedade ou segmentos dela, descartando do humano, pelo mesmo princípio, o que contraria esses padróes. Se é próprio do humano criar, o é também destruir; se é próprio do humano estabelecer limites (normas éticas, morais, jurídicas etc.), o é também transgredi-los; se é próprio do humano amar, o é também odiar. Sem possibilidade ontológica de destruir, transgredir e odiar, é impossível criar, estabelecer limites e amar.

Isso mostra que a questáo do bumano esconde toda a complexidade desse ser que se desgarrou da família dos primatas e se tornou o demiurgo de si mesmo. A questáo do humano mostra também que só existe um caminho ao homem: tornar possível a convivência de todos com todos, encontrando e assumindo coletivamente as formas mais aceitáveis por todos para conseguir essa convivência. Utopia? Certamente, mas é a única maneira de o homem — não o homem genérico abstrato, mas o homem genérico concreto — sobreviver a si mesmo.

\section{Notas}

1. Lev S. Vygotsky é o grande líder do grupo de autores que formam a corrente de psicologia surgida na Rússia na época da Revolução de 1917 e que ficou conhecida como "Escola Soviética" de psicologia, nome que remete não só ao seu lugar de origem, mas, sobretudo, à perspectiva marxista que ela representa.

2. "Culture is both a product of social life and of the social activity of man".

3. "Every function in the cultural development of the child appears on the stage twice, in two planes, first the social, then the psychological, first between people, as an intermental category, then within the child as an intramental category".

4. "O que é o homem? Para Hegel é o sujeito lógico. Para Pavlov é a soma, o organismo. Para nós é a personalidade social $=$ o conjunto de relaçôes sociais encarnado no indivíduo (funçôes psicológicas construídas pela estrutura social)" (VYGOTSKY, 2000, p. 33).

5. Assunto de duas versôes diferentes dessa temática: a do biogeneticista Francis Fukuyama (2003) e a do filósofo Jürgen Habermas (2003), cuja crítica é feita por Zizek (2003).

6. "We can formulate the general genetic law of cultural development as follows: every function in the cultural development of the child appears on the stage twice, in two planes, first the social, then the psychological, first between people as an intermental category, then within the child, as a intramental category". 


\section{Referências}

BAKHTIN, M. Marxismo e filosofia da linguagem. São Paulo: Hucitec, 1981.

CASTORIADIS, C. L'institution imaginaire de la société. Paris: Editons du Seuil, 1975.

FUKUYAMA, F. Nosso futuro pós-humano. Rio de Janeiro: Rocco, 2003.

HABERMAS, J. O futuro da natureza humana. São Paulo: Martins Fontes, 2003.

HEGEL, G.W.F. Fenomenologia do Espirito. Rio de Janeiro: Vozes, 1992.

KURZWEIL, R. Ser humano: versão 2.0. Folha de S.Paulo-Mais!, 23 mar. 2003.

MARX, K. Le capital. Paris: Éditions Sociales de France, 1977. Livro I.

; ENGELS, F. A ideologia alemã. São Paulo: Martins Fontes, 1989.

NIETZSCHE, F. Ecce Homo. São Paulo: Companhia das Letras, 1995.

REES, M. Our final hour. Nova York: Basic Books, 2003.

VYGOTSKY, L. S. Manuscrito de 1929. Educação \& Sociedade, Campinas, v. 21, n. 71, 2000. http://dx.doi.org/10.1590/S0101-73302000000200002

The history of the development of higher mental functions. In: RIEBER, R.; HALL, M.J.; GLICK, J. (Orgs.). Collected Works of L. S. Vygotsky. Nova York: Plenum Press, 1997. v. 4.

ZIZEK, S. A falha da bio-etica. Folha de S.Paulo Mais!, 22 jun. 2003.

\section{Nota de Apresentação}

\section{Ana Luiza SMOLKa ${ }^{1}$}

Grande entusiasta e incentivador da Revista Educação e Sociedade desde seu início, tendo dela participado como autor e parecerista ad hoc, o Professor Angel Pino nela publicou diversos artigos, abrangendo temáticas como as políticas públicas e a educação, a violência e a marginalidade, o desenvolvimento humano na história e na cultura. Dentre suas preciosas contribuiçóes, colocamos em destaque neste momento um artigo publicado em 1992 (PINO, 1992), no qual ele admitia o fosso teórico que separava a natureza da cultura nas ciências humanas, e procurava equacionar o problema da emergência das funçóes mentais especificamente humanas, discutindo, pelo prisma das categorias de público e privado, uma das teses principais de L.S. Vygotsky sobre a natureza social do desenvolvimento humano. O dossiê temático sobre a Constituição Cultural do Homem (PINO, 2000) por ele organizado e publicado no ano 2000, constitui um marco importante para os pesquisadores na perspectiva histórico-cultural, uma vez que inclui a tradução para o português, feita diretamente do russo, do Manuscrito de

${ }^{1}$ Universidade Estadual de Campinas, Faculdade de Educação - Campinas (SP), Brasil 
1929, de Vygotsky. Neste dossiê, Pino também nos brinda com um artigo que já se tornou um clássico nesta perspectiva teórica (PINO, 2000), onde ele retoma e analisa pressupostos e argumentos indicados e não necessariamente explicitados nos escritos do autor russo. $\mathrm{O}$ ano de 2009 traz um interessante desafio, com as comemoraçōes do bicentenário de Darwin. Desde sempre engajado nos debates sobre o biológico e o cultural na constituição humana, Pino se dedica ao estudo aprofundado da obra do naturalista inglês, adensando e expandindo o diálogo com os trabalhos de Vygotsky (PINO, 2009). Na celebração dos 40 anos da Revista Educação e Sociedade, homenageamos o Professor Pino publicando um texto que corresponde ao trabalho por ele apresentado no XII ENDIPE (PINO, 2004), em 2004, e que consiste numa bela síntese de seus estudos e reflexóes sobre as relaçóes homem-natureza, natureza-cultura, evidenciando sua incansável preocupação com as condições históricas e culturais de humanização e sua singular contribuiçáo para o campo da Educação, ao sistemática e intensamente inquirir e teorizar sobre as marcas do humano no homem.

\section{Referências}

PINO, A. As categorias de público e privado na análise do processo de internalizaçáo. Educação e Sociedade, Ano XIII, n. 42, p. 315-327, 1992.

. Ciência e Educação: a propósito do bicentenário do nascimento de Charles Darwin. Educação e Sociedade, Campinas, v. 30, n. 108, p. 845-866, out. 2009. http:// dx.doi.org/10.1590/S0101-73302009000300011

. O social e o cultural na obra de Vygotsky. Educação e Sociedade, v. 21, n. 71, p. 45-75, 2000. http://dx.doi.org/10.1590/S0101-73302000000200003

As marcas do humano. In: XII ENCONTRO NACIONAL DE DIDÁTICA E PRÁTICA DE ENSINO (ENDIPE), Curitiba, 2004.

Recebido em 02 de janeiro de 2018.

Aceito em $1^{\circ}$ de fevereiro de 2018.

(C) 2018 Centro de Estudos Educação e Sociedade - CEDES Este é um artigo de acesso aberto distribuído nos termos de licença Creative Commons. 